\title{
Teste de um Sucedâneo na Produção de Vitelos ${ }^{1}$
}

\author{
Pedro Afonso Moreira Alves², Rosane Scatamburlo Lizieire ${ }^{2}$
}

RESUMO - o objetivo deste trabalho foi avaliar o desempenho de vitelos recebendo leite integral ou sucedâneo do leite especial para vitelos. Foram utilizados 30 bezerros, do nascimento aos 160-170 kg de peso vivo, distribuídos nos seguintes tratamentos experimentais: I - leite integral, II - leite integral até os $100 \mathrm{~kg}$ de peso vivo e, a partir daí, o aumento na quantidade de dieta líquida foi feito com o sucedâneo de terminação, adicionado ao leite, até o abate e III - leite até o $10^{0}$ dia de vida e, a partir daí, o sucedâneo inicial até atingir $100 \mathrm{~kg}$ de peso vivo, passando, então, para o sucedâneo de terminação, até o abate. Não houve diferença significativa entre os tratamentos para o ganho de peso médio diário (NS), a idade de abate ( $\mathrm{P}=0,06701)$ e o rendimento de carcaça $(\mathrm{P}=0,21527)$; entretanto, os animais do tratamento III, que receberam o sucedâneo de leite, apresentaram consumo de matéria seca significativamente maior $(\mathrm{P}=0,00055)$ e, conseqüentemente, pior conversão alimentar $(\mathrm{P}=0,00021)$. Não houve diferença entre tratamentos para o número de dias com diarréia e a incidência de corrimento nasal foi insignificante. Seria economicamente vantajoso utilizar o sucedâneo comercial para vitelos, testado neste ensaio, se o preço do $\mathrm{kg}$ do produto (pó) fosse 6,4 vezes menor que o preço de um litro de leite integral.

Palavras-chave: bezerros, desempenho, sucedâneos do leite, vitelos

\section{Test of a Milk Replacer for Veal Calves}

\begin{abstract}
The objective of this trial was to evaluate the performance of veal calves fed whole milk or milk replacers. Thirty Holstein calves from birth up to $160-170 \mathrm{~kg}$ of body weight were randomly allotted to the following experimental treatments: I-whole milk; II- whole milk up to $100 \mathrm{~kg}$ of body weight, and from this weight on, the supply of more liquid diet was from a commercial finishing milk replacer, added to the milk, up to slaughter; III-whole milk up to the $10^{\text {th }}$ day of life, starter commercial milk replacer up to $100 \mathrm{~kg}$ of body weight and finishing commercial milk replacer up to slaughter. There was no significant difference among treatments for calves daily weight gain $(\mathrm{NS})$, age at slaughter $(\mathrm{P}=.06701)$ and carcass rate $(\mathrm{P}=0,21527)$; however, calves on treatment III showed higher dry matter feed intake $(\mathrm{P}=.00055)$ and, consequently lower feed efficiency $(\mathrm{P}=.00021)$. There was no significant difference among treatments for scours $(\mathrm{P}>.05)$ and nasal flow. The utilization of the tested milk replacer would be economically feasible if the price of $1 \mathrm{~kg}$ of de product (powder) would be lower than 6.4 times the price of $1 \mathrm{~kg}$ of whole milk.
\end{abstract}

Key Words: calves, milk replacers, performance, veal

\section{Introdução}

Nos países de pecuária leiteira desenvolvida, o aproveitamento dos bezerros de rebanhos leiteiros para a produção de carne é uma realidade, representando parcela significativa da carne consumida pela população. Existem vários sistemas com este objetivo. Na Holanda, França e Itália, principalmente, e em menor escala nos Estados Unidos e Canadá, bezerros, predominantemente de raças leiteiras, são abatidos às 16-18 semanas de idade com 160-170kg de peso vivo. Trata-se da produção de vitelos, caracterizada pela alimentação dos animais exclusivamente com leite e/ou sucedâneos especiais do leite, e produção de carcaças com carne branca, tenra e própria para preparo de pratos sofisticados (CAMPOS et al., 1997).
A produção de vitelos desenvolveu-se na Europa e na América do Norte nos últimos 30 a 40 anos, como resultado da demanda por carnes especiais, pela abundância de subprodutos lácteos (leite em pó desengordurado e soro de leite) e pela grande disponibilidade de bezerros oriundos de rebanhos leiteiros (TOULLEC, 1988). Em países onde a produção de leite representa segmento importante da economia, como na Holanda, a produção de vitelos tornou-se economicamente importante, devido à utilização de leite em pó na alimentação dos animais. O sucesso da indústria de vitelos foi devido, principalmente, ao fato de as indústrias terem conseguido substituir a gordura do leite por outros tipos de gordura, quando da formulação dos sucedâneos (KEMPEN e HUISMAN, 1991). Neste sentido, as pesquisas sobre qualidade da gordura e emulsificantes tiveram papel importante

\footnotetext{
${ }^{1}$ Projeto financiado pela FAPERJ.

2 Pesquisadores da PESAGRO-RIO, Estação Experimental de Itaguaí, Estrada Rio-São Paulo, km 47 - CEP: $23.851-970$, Seropédica, RJ. E.mail:eei@domain.com.br
} 
(HUISMAN e WEERDEN, 1984; TOULLEC et al., 1980).

Os níveis de proteína e energia são os mais importantes na escolha do sucedâneo de leite; os de proteína, normalmente variam de 18 a $22 \%$ e os de gordura, de 10 a 22\% (QUIGLEY, 1998). Para vitelos, entretanto, segundo TOULLEC (1988), estes valores devem ser de 20,5 e $20 \%$, respectivamente. $\mathrm{O}$ aumento do custo da proteína do leite, tradicionalmente utilizada em sucedâneos para vitelos, tem estimulado a necessidade de substituir parte da mesma por fontes alternativas. Dentre elas, as proteínas da soja, trigo, batata, ervilha, peixe e levedura têm sido muito estudadas. Segundo KOLAR e WAGNER (1991), alguns fatores têm sido considerados mais importantes, como a composição química, fatores antinutricionais, digestibilidade, composição de aminoácidos, propriedades físicas e microbiológicas, além da economicidade e comercialização, quando se estudam sucedâneos para vitelos.

A utilização de produtos não lácteos em sucedâneos de leite tem mostrado resultados inferiores aos obtidos com a utilização do leite (CAMPOS, 1982; HUBER e CAMPOS, 1982; QUIGLEY, 1998). Parece que a utilização de proteínas não lácteas prejudica a formação do coágulo no abomaso (PETIT et al., 1989; CAUGANT et al., 1994). Com a formação do coágulo, em dietas baseadas em leite em pó, a proteína permanece mais tempo no abomaso, apresentando menor taxa de passagem e, conseqüentemente, maior exposição à pepsina e $\mathrm{HCl}$. Nestes animais, o intestino delgado é regularmente cheio com proteína e gordura, quando comparados com bezerros recebendo dietas à base de soja (KEMPEN e HUISMAN, 1990). Segundo esses autores, os emulsificadores utilizados para vitelos foram desenvolvidos para dietas contendo proteína do leite, como principal fonte protéica, havendo necessidade de novos estudos para redefinir as qualidades e propriedades destes emulsificadores, quando utilizados em sucedâneos com outro tipo de proteína.

Fatores antinutricionais têm individualmente, ou em associação, efeitos negativos sobre o crescimento e/ou saúde dos bezerros (LÁLLES, 1993). Esses fatores poderiam agir, principalmente, sobre a digestão e absorção da proteína e aminoácidos, mas poderiam influenciar, também, a digestão de carboidratos, utilização de minerais e disponibilidade de vitaminas. O SBTI (fator antitripsínico), presente na soja, reduz a secreção de tripsina e quimotripsina, resultando em menor digestão da proteína (GORRILL e THOMAS,
1967; TERNOUTH e ROY, 1973; KHORASANI et al., 1989). As proteínas antigênicas induzem a síntese de anticorpos específicos quando ingeridas pelos animais. A glicina e beta conglicina, principais estoques de globulinas, representam mais que $60 \%$ do conteúdo de proteína da soja e têm sido relacionadas com o desenvolvimento de reações alérgicas no intestino (SISSONS, 1982; LALLÉS e DREAU, 1996).

Outro aspecto que deve ser levado em conta em sucedâneos de leite para vitelos é o seu conteúdo de ferro, que necessita ser baixo. A disponibilidade de ferro pode diferir marcadamente entre as diferentes fontes de proteína. Weerden et al. (1977, 1978), citados por KEMPEN e HUISMAN (1991), demonstraram que a disponibilidade de ferro em produtos de peixe é alta e em concentrado de soja, baixa. Segundo os autores, é possível reduzir a disponibilidade do ferro nestes alimentos, utilizando agentes especiais, como o EDTA.

Como resultados, os bezerros têm apresentado menores ganhos de peso e eficiência alimentar, baixas digestibilidades da matéria seca, proteína e gordura (NITSAN et al., 1971; MILLER et al., 1991), menor absorção intestinal (SEEGRABER e MORRIL, 1979), menor retençao de nitrogênio e aumento nos casos de diarréias (SILVA et al., 1986), além de deterioração gradual na integridade das vilosidades, em conseqüência de reações alérgicas (SILVA et al., 1986; SEEGRABER e MORRILL, 1986). Segundo KOLAR e WAGNER (1991), parece que a proteína isolada de soja e a proteína concentrada de soja, tratada com álcool, apresentam os melhores resultados, quando utilizadas em sucedâneos para vitelo, devido à maior digestibilidade (88\%), menor nível de fatores antinutricionais e melhores propriedades físicas. LAPORTE et al. (1991) comenta que a proteína solúvel de trigo pode ser uma alternativa para substituir o leite em pó desnatado em sucedâneos para bezerros. Entre as razões, ela possui alta digestibilidade (95\%) e solubilidade, capacidade de emulsificação e estabilidade na emulsão, baixo teor de ferro (30 mg/kg) e baixa digestibilidade deste mineral, favorecendo a cor da carne. Além disto, segundo o autor, não se conhecem fatores antinutricionais ou alérgicos neste ingrediente.

Em sistemas de produção de vitelos, o custo final de produção depende, principalmente, do gasto com alimentação, normalmente elevado, tendo em vista que o leite integral ou sucedâneos especiais do leite constituem-se na única fonte de nutrientes para os animais. 
No Brasil, existem poucas informações sobre a produção de vitelos e os trabalhos conduzidos até o momento utilizaram o leite integral, uma vez que os sucedâneos do leite especiais para vitelos são, no mercado nacional, em disponibilidade muito pequena. Nesse sentido, o presente experimento foi conduzido, utilizando um produto importado, com o objetivo de estudar tanto o desempenho dos animais quanto a economicidade do produto.

\section{Material e Métodos}

O experimento foi conduzido na Fazenda Santa Lúcia, localizada no km 27 da Rodovia RJ 151, município de Rio das Flores, em Rio das Flores, região do Médio Paraíba, do Estado do Rio de Janeiro, no período de outubro de 1997 a abril de 1998.

Foram utilizados 30 bezerros machos mestiços Holandês x Gir, com uma semana de idade, nascidos no período de outubro de 1997 a abril de 1998 e alimentados exclusivamente com dieta líquida. Foram utilizados o leite integral ou um sucedâneo inicial, Denkavit veal starter (96\%MS, 21,5\%PB e $19,5 \%$ gordura), e de terminação, Denkavit veal finisher (96\% MS, 22,\% PB, 22,6\% de gordura). Os animais foram distribuídos, em 10 blocos ao acaso de acordo com o peso ao nascer, nos seguintes tratamentos experimentais: $\mathrm{I}=$ leite integral; II = leite integral até os $100 \mathrm{~kg}$ de peso vivo e a partir daí, o aumento na quantidade de dieta líquida foi feito com o sucedâneo de terminação, adicionado ao leite, até o abate; e III = leite integral até o $10^{\mathrm{O}}$ dia de vida e, a partir daí, sucedâneo inicial até atingir $100 \mathrm{~kg}$ de peso vivo, passando, então, para o sucedâneo de terminação, até o abate.

Os bezerros foram comprados de produtores de leite e selecionados para o experimento, de acordo com o peso, sempre superior a $35 \mathrm{~kg}$, aparência geral, vivacidade e conformação. Além disso, para estimar a concentração de imunoglubulinas e verificar o status imunológico do animal, foi feito o teste do glutaraldeído (CHARLES et al., 1994), no momento do desembarque. Animais que apresentaram resultado negativo foram imediatamente descartados. Após estas avaliações, os animais foram pesados e conduzidos para o bezerreiro.

A alimentação, constituída exclusivamente da dieta líquida, foi fornecida em duas refeições diárias, em mamadeira, às 8 e 16 h. O sucedâneo foi diluído em água, à temperatura ambiente, na proporção de $180 \mathrm{~g}$ do produto para 1 litro de água. Os bezerros que receberam sucedâneo passaram, na fase inicial, por um período de três dias de adaptação, recebendo 25; 50 e $75 \%$ do produto, respectivamente.

Os animais com peso inicial até $40 \mathrm{~kg}$ receberam quatro litros de dieta líquida/animal/dia e aqueles com peso superior a este, seis litros de dieta líquida/animal/ dia, até o $10^{\mathrm{o}}$ dia. A partir daí, a quantidade da dieta líquida fornecida foi equivalente a $13,5 \%$ do peso vivo do animal, ajustada a cada 14 dias.

A instalação utilizada foi um estábulo de vacas, desativado, orientado no sentido Este-Oeste, com duas linhas de cocho dispostas frente a frente. Sobre a parede frontal de cada cocho, a altura de $0,6 \mathrm{~m}$ do chão, havia um bebedouro de calha com água corrente. Os cochos foram separados por um corredor central. A cobertura era de telha francesa com pé direito de $2,8 \mathrm{~m}$, sem paredes. Os bezerros foram contidos por coleiras com corda de um metro de comprimento. A distância entre os animais foi de 1,20 m, que impedia que os mesmos se tocassem. No piso de cimento, foi utilizada cama de serragem, que era trocada sempre que necessário.

Na primeira e quarta semanas de idade, os bezerros receberam vacina contra Salmonella, para prevenir diarréias. Na segunda semana, os bezerros receberam $1 \mathrm{~mL}$ de ivermectina para controle de endo e ecto parasitas, $3 \mathrm{~mL}$ de terramicina e $3 \mathrm{~mL}$ de ganazeg, como preventivo para babesiose e anaplasmose. Diariamente foi observada a consistência das fezes e, quando necessário, foi realizado tratamento com produto oral, à base de clorofenicol. Não foi aplicado nenhum medicamento nas duas semanas que antecederam aos abates, os quais foram realizados em abatedouro frigorífico, quando os animais atingiram peso vivo entre 150 e $190 \mathrm{~kg}$.

Foram feitas as seguintes mensurações:

1. Pesagens semanais, sempre antes da alimenta ção da manhã

2. Consumo diário de alimentos

3. Conversão e eficiência alimentar

4. Peso de abate

5. Idade de abate

6. Incidência diária de diarréia

7. Incidência diária de corrimento nasal

8. Rendimento de carcaça

Com relação à incidência de diarréias, os animais foram obervados diariamente pela manhã, aos quais foi dado um escore: (1) se as fezes fossem consideradas normais, mesmo que ligeiramente fluídas, e (2) se as fezes fossem consideradas líquidas.

Os resultados de desempenho foram submetidos 
a análises de variância. O delineamento empregado foi em blocos ao acaso (GOMES, 1990), sendo as médias dos fatores quantitativos foram comparadas pelo teste de Tuckey, adotando-se o nível de 5\% de probabilidade. As análises estatísticas foram realizadas utilizando-se o Sistema de Análises Estatísticas Genéticas - SAEG (EUCLIDES, 1990). Os dados relacionados com incidência de diarréias foram analisados pelo teste do Qui-quadrado $\left(\mathrm{c}^{2}\right)$.

\section{Resultados e Discussão}

Na Tabela 1 são apresentados os resultados obtidos no período total, do nascimento ao abate, com relação ao peso médio inicial, consumo de matéria seca, ganho de peso médio diário, conversão alimentar, peso e idade ao abate e rendimento de carcaça.

O consumo total de matéria seca foi significativamente menor para os animais que receberam leite integral $(\mathrm{P}=0,00055)$ do que aqueles recebendo o sucedâneo comercial de leite (tratamento III). Os animais que receberam leite integral até $100 \mathrm{~kg}$ de peso vivo e, a partir daí, o sucedâneo de terminação apresentaram consumo de matéria seca semelhante àqueles alimentados com leite integral ou somente sucedâneo. Não houve diferença significativa (NS) para o ganho de peso médio diário entre os tratamentos experimentais, conseqüentemente, a conversão alimentar (kg de matéria seca consumida/kg de ganho de peso) $(\mathrm{P}=0,00021)$ e a eficiência $(\mathrm{kg}$ de ganho/kg de matéria seca consumida) $(\mathrm{P}=0,00020)$ foram piores para os animais que receberam somente o sucedâneo. Não houve diferença significativa entre os tratamentos para o rendimento de carcaça $(\mathrm{P}=0,21527)$, idade $(\mathrm{P}=0,06701)$ e peso dos animais ao abate, sendo que este último foi estabelecido, ao início do experimento, entre 150 e $190 \mathrm{~kg}$.

Em relação ao consumo de matéria seca, os resultados obtidos neste ensaio foram semelhantes àqueles de ALVES (1999), que obteve consumo médio de matéria seca de 1,48 kg/animal/dia com bezerros recebendo leite integral. Entretanto, o consumo de matéria seca aumentou significativamente ( $\mathrm{P}=0,00055)$, quando comparado com os animais recebendo sucedâneo comercial de leite, estando próximo ao obtido por EGGER e HILFIKER (1992),

Tabela 1 - Efeito dos tratamentos experimentais sobre o consumo de dieta líquida, consumo de matéria seca (MS), ganho de peso médio diário, eficiência alimentar ( $\mathrm{kg}$ de ganho/kg de matéria seca consumida), conversão alimentar ( $\mathrm{kg}$ de matéria seca consumida/kg de ganho de peso), peso e idade ao abate, no período total do experimento

Table 1 - Treatments effects on liquid and dry matter intakes, average daily gain, feed efficiency ( $\mathrm{kg}$ of gain/ $\mathrm{kg}$ of dry matter intake), feed: gain ratio ( $\mathrm{kg}$ of dry matter intake/kg of weight gain), age and weight at slaughter in the total experimental period

\begin{tabular}{|c|c|c|c|}
\hline \multirow[b]{2}{*}{$\begin{array}{l}\text { Variáveis } \\
\text { Variables }\end{array}$} & \multicolumn{3}{|c|}{$\begin{array}{l}\text { Tratamento } \\
\text { Treatment }\end{array}$} \\
\hline & $\begin{array}{l}\text { Leite integral } \\
\text { Whole milk }\end{array}$ & $\begin{array}{l}\text { Leite integral + sucedâneo } \\
\text { de terminação } \\
\text { Whole milk and finishing } \\
\text { type milk replacer }\end{array}$ & $\begin{array}{l}\text { Sucedâneos } \\
\text { Milk replacers } \\
\text { (starter and } \\
\text { finishing types) }\end{array}$ \\
\hline $\begin{array}{l}\text { Peso inicial, } \mathrm{kg} \\
\text { Inicial body weight, } \mathrm{kg}\end{array}$ & $41,14 \pm 0,611$ & $42,14 \pm 0,611$ & $40,82 \pm 0,611$ \\
\hline $\begin{array}{l}\text { Consumo de dieta líquida, } \mathrm{L} \\
\text { Liquid diet intake, } L\end{array}$ & $1412 \pm 60$ & $1286 \pm 60$ & $1363 \pm 60$ \\
\hline $\begin{array}{l}\text { Consumo de MS, } \mathrm{kg} / \text { animal.dia } \\
\text { Dry matter intake, kg/animal.day }\end{array}$ & $1,40^{\mathrm{b}} \pm 0,058$ & $1,52^{\mathrm{ab}} \pm 0,058$ & $1,79^{\mathrm{a}} \pm 0,058$ \\
\hline $\begin{array}{l}\text { Ganho de peso, kg/animal.dia } \\
\text { Weight gain, kg/animal.day }\end{array}$ & $0,930 \pm 0,0354$ & $0,988 \pm 0,0354$ & $0,948 \pm 0,0354$ \\
\hline $\begin{array}{l}\text { Eficiência alimentar } \\
\text { Feed efficiency }\end{array}$ & $0,709^{a} \pm 0,0229$ & $0,728^{a} \pm 0,0229$ & $0,569^{b} \pm 0,0229$ \\
\hline $\begin{array}{l}\text { Conversão alimentar } \\
\text { Feed:gain ratio }\end{array}$ & $1,43^{\mathrm{a}} \pm 0,0569$ & $1,39^{a} \pm 0,0569$ & $1,78^{\mathrm{b}} \pm 0,0569$ \\
\hline $\begin{array}{l}\text { Peso ao abate, } \mathrm{kg} \\
\text { Weight at slaughter, } \mathrm{kg}\end{array}$ & $165,6 \pm 3,996$ & $165,8 \pm 3,996$ & $165,9 \pm 3,996$ \\
\hline $\begin{array}{l}\text { Idade ao abate, dias } \\
\text { Age at slaughter, days }\end{array}$ & $126,9 \pm 3,831$ & $114 \pm 3,831$ & $124 \pm 3,831$ \\
\hline $\begin{array}{l}\text { Rendimento de carcaça, \% } \\
\text { Carcass yield, \% }\end{array}$ & $55 \pm 0,73$ & $57 \pm 0,73$ & $56 \pm 0,73$ \\
\hline
\end{tabular}


Rev. bras. zootec.

em média $1,88 \mathrm{~kg} / \mathrm{dia}$, quando suplementaram o leite integral com sucedâneo de leite, a partir dos $100 \mathrm{~kg}$ de peso vivo.

Não houve diferença significativa para o ganho de peso médio diário, entre os tratamentos experimentais. ALVES (1999) também obteve ganhos semelhantes $(0,918 \mathrm{~kg} / \mathrm{animal} / \mathrm{dia})$, quando utilizou leite integral na alimentação dos animais. Para bezerros alimentados com sucedâneos de leite, foram obtidos ganhos de peso médios diários variando de 0,850 a 0,950 g/animal/dia (KNAUS et al., 1994; RONDA e RONDA, 1994). Já ELLIOTT et al. (1989), embora não tenham encontrado diferença no ganho de peso e na qualidade da carcaça, comentam que o custo final do bezerro foi reduzido, quando utilizaram sucedâneos em que a proteína do leite foi parcialmente substituída pela de soja. Ganhos de peso superiores foram obtidos por TOLMAN et al. (1991), em média 1,2 kg/ animal/dia, quando utilizaram a proteína solúvel de trigo em sucedâneos para vitelos, mas a conversão alimentar obtida por estes autores, em torno de 1,78, foi próxima à maioria dos experimentos realizados com sucedâneos de leite.

Com relação à conversão alimentar, os animais alimentados com o sucedâneo de leite apresentaram piores resultados $(\mathrm{P}=0,00021)$, porém semelhantes àqueles obtidos por RONDA e RONDA (1994) e KNAUS et al. (1994), que obtiveram conversões alimentares variando de 1,54 a 1,75, quando substituíram parte da proteína láctea pela proteína concentrada ou hidrolisada de soja. TOULLEC et al. (1994), também obtiveram piores conversões alimentares e menor peso final de abate, quando utilizaram sucedâneos a base de proteína concentrada de soja, Segundo TOULLEC et al. (1994), o pior desempenho de bezerros alimentados com sucedâneos comerciais de leite pode ser devido, principalmente, à menor digestibilidade do produto. EGGER (1992) acrescenta que bezerros alimentados com sucedâneos, além de apresentarem piores conversões, podem produzir carne mais avermelhada devido aos níveis sangüíneos de hemoglobina mais elevados. No presente ensaio, embora não tenha sido feita a avaliação dos níveis de hemoglobina, os restaurantes de cozinha internacional que adquiriram a carne, muito exigentes com relação à coloração da mesma, não detectaram qualquer diferença entre os bezerros que receberam leite e/ou sucedâneo.

Como os animais do tratamento leite integral + sucedâneo de terminação (tratamento II) passaram a receber o sucedâneo a partir dos $100 \mathrm{~kg}$ de peso vivo, aproximadamente com 8-10 semanas de idade, foi feita uma análise estatística para o período de 0 a 8 semanas de idade e a partir das 9 semanas até o abate. Os dados mostraram a mesma tendência quando comparados com o período total do experimento. Os ganhos de peso médios diários foram semelhantes (NS), nos dois períodos analisados, para os três tratamentos experimentais. O consumo de matéria seca foi significativamente maior $(\mathrm{P}=0,00062)$, de zero a oito semanas e de nove semanas ao abate $(\mathrm{P}=0,00107)$, para os animais recebendo somente sucedâneo e, conseqüentemente, a eficiência alimentar desses animais foi pior $(\mathrm{P}=0,03441)$, de zero a oito semanas de idade e de nove semanas de idade ao abate $(\mathrm{P}=0,02811)$, principalmente a partir das nove semanas de idade até o abate.

Na Tabela 2 podem ser observados os resultados obtidos com relação à incidência de diarréia, expressos em total de dias com fezes fluídas (diarréia), número de dias sem medicação e total de dias que os animais receberam medicação para tratamento de diarréia.

Em sistemas de produção de vitelos, as perdas por descarte, doença ou morte devem ser minimizadas, uma vez que a margem de lucro por bezerro é pequena (CAMPOS et al., 1997). Neste sentido, o controle de diarréias deve ser uma preocupação constante. Historicamente, os maiores problemas com a utilização de sucedâneos do leite para bezerros têm sido: excesso de amido e fibra, tipo e incorporação inadequada da gordura e utilização de fontes protéicas de baixo aproveitamento ou que provocam transtornos digestivos nos bezerros (SILVA e CAMPOS, 1986; SILVA et al., 1986). A menor absorção intestinal (SEEGRABER e MORRIL, 1979), a reduzida retenção de nitrogênio, além de deterioração gradual na integridade das vilosidades intestinais (SEEGRABER e MORRIL, 1982, 1985), em conseqüência de reações alérgicas (SILVA et al., 1986; SEEGRABER e MORRILL, 1986), podem aumentar os casos de diarréias. No presente ensaio, não houve diferença significativa $(\mathrm{P}>0,01)$ entre os tratamentos experimentais em relação ao número de dias com fezes fluídas e número de dias sob medicação. Como, normalmente, os problemas com diarréia começam logo nas primeiras semanas, estes resultados confirmam a boa qualidade do sucedâneo utilizado. A incidência de corrimento nasal também foi insignificante para todos os tratamentos experimentais, não sendo necessário qualquer tratamento terapéutico.

Pelos resultados obtidos neste experimento, embora 
Tabela 2 - Efeito dos tratamentos experimentais sobre o número de dias com fezes fluídas e o números de dias sob medicação durante o período experimental

Table 2 - Treatment effects on scours and number of days under medication during the experimental period

\begin{tabular}{|c|c|c|c|c|c|c|}
\hline & $\begin{array}{l}\text { Fezes normais } \\
\quad \text { (dias) } \\
\text { Normal feces } \\
\quad(\text { days })\end{array}$ & $\begin{array}{l}\text { Fezes fluidas } \\
\text { (dias) } \\
\text { Fluidfeces } \\
\text { (days) }\end{array}$ & $\begin{array}{c}\text { Total } \\
\text { (dias) } \\
\text { Total } \\
(\text { days })\end{array}$ & $\begin{array}{l}\text { Dias sem } \\
\text { medicação } \\
\text { Days without } \\
\text { medication }\end{array}$ & $\begin{array}{l}\text { Dias com } \\
\text { medicação } \\
\text { Days under } \\
\text { medication }\end{array}$ & $\begin{array}{c}\text { Total } \\
\text { (dias) } \\
\text { Total } \\
\text { (days) }\end{array}$ \\
\hline $\begin{array}{l}\text { Leite integral } \\
\text { Whole milk }\end{array}$ & 1252 & 17 & 1269 & 1269 & 0 & 1269 \\
\hline $\begin{array}{l}\text { Leite integral + sucedâneo } \\
\text { de terminação } \\
\text { Whole milk and finishing } \\
\text { type milk replacer }\end{array}$ & 1118 & 22 & 1140 & 1140 & 0 & 1140 \\
\hline $\begin{array}{l}\text { Sucedâneos } \\
\text { Milk replacers } \\
\text { (starter and finishing types) }\end{array}$ & 1205 & 37 & 1242 & 1239 & 3 & 1242 \\
\hline Total & 3575 & 76 & 3651 & 3648 & 3 & 3651 \\
\hline
\end{tabular}

a conversão alimentar dos animais que receberam somente o sucedâneo comercial de leite (tratamento III) tenha sido pior, não houve efeito dos tratamentos experimentais para ganho de peso diário, idade de abate, incidência de diarréias e corrimento nasal. Portanto, a principal diferença entre os tratamentos estudados seria o custo de produção desses animais, relacionado com o consumo de alimentos. No tratamento I, foram gastos, em média, 1412 litros de leite integral (Tabela 1) e no tratamento III, $222 \mathrm{~kg}$ de pó do sucedâneo comercial, por animal, durante todo o período de produção. Assim, seria economicamente vantajoso utilizar o sucedâneo comercial se o preço do $\mathrm{kg}$ de sucedâneo (pó) fosse 6,4 vezes menor que o preço de um litro do leite integral. No presente experimento, os sucedâneos inicial e de terminação foram adquiridos a um custo de $\mathrm{R} \$ 2,42$ e $\mathrm{R} \$ 2,16 / \mathrm{kg}$, respectivamente. Como o preço médio do leite integral por ocasião da realização deste ensaio ficou em torno de $\mathrm{R} \$ 0,25$ por litro, não houve vantagem econômica em se utilizar o sucedâneo comercial para a produção desses vitelos.

\section{Conclusões}

Nas condições do presente experimento, pode-se concluir que os animais alimentados com o sucedâneo comercial de leite apresentaram maior consumo de matéria seca total e, conseqüentemente, pior conversão alimentar, quando comparados com os animais que receberam leite integral. Entretanto, este resultado não influenciou o peso final e a idade de abate dos animais, uma vez que o ganho de peso médio diário foi semelhante entre os tratamentos. Portanto, a decisão de se utilizar leite integral ou sucedâneo comercial dependerá basicamente da relação de preços existente entre estes dois alimentos, quando da implantação do sistema para produção dos vitelos.

\section{Referências Bibliográficas}

ALVES, P.A.P.M. Uso de leite integral ou sucedâneo comercial, come sem probióico, na produção de vitelos. Seropédica, RJ: UFRRJ, 1999. 54p. Dissertação (Mestrado em Zootecnia). Departamento de Zootecnia/Universidade Federal Rural do Rio de Janeiro, 1999.

CHARLES, T.P., CAMPOS, O.F., LIZIEIRE, R.S. 1994. Uso do teste de coagulação pelo glutaraldeído como indicador do nível de imunoglobulinas no soro e sangue de bezerros recémnascidos. R. Soc. Bras. Zootec., 23(1):65-72.

CAMPOS, O.F. Spray-dried fish solubles, soy protein concentrate and limestone in milk replacers for young calves. East Lansing: Michigan State University, 1982. 126p. (PhD Thesis). Michigan State University, 1982.

CAMPOS, O.F., LIZIEIRE, R.S., ALVES, P.A.P.M. 1997. Produção de vitelos. Juiz de Fora: Embrapa-CNPGL. 22p (Circular Técnica, 42).

CAUGANT, I., PETIT, H.V., IVAN, M. et al. 1994. In vivo and in vitro gastric emptying of milk replacers containing soybean proteins. J. Dairy Sci., 77(2):533-540.

EGGER, I., HILFIKER, J. 1992. Aventages d'une alimentation rationnée chez le veau à l'engrais. Rev. Suisse Agric., 24(4):219-224.

EGGER, I. 1992. Sous-produits laitiers dans l'engraissement des veaux. Rev. Suisse Agric., 24(3):153-158.

ELLIOT, J.G., BLACK, W.T., GEURIN, H.B. 1989. Effect of an isolated soy protein based product and whey on partial replacement of dried skim milk and whey protein concentrate in a milk replacer for veal calves. J. Dairy Sci., 72 (Suppl. 1): 242-243.

EUCLIDES, R.F. 1990. Sistema de análise estatística genética. Viçosa: UFV. 68p.

GOMES, F.P. 1990. Curso de estatística experimental. 13.ed. Piracicaba: USP/ESALQ. 468p. 
Rev. bras. zootec.

GORRILL, A.D.L., THOMAS, J.W. 1967. Proteolytic activity of the bovine pancreas. J. Dairy Sci., 24(2):882.

HUBER, J.T., CAMPOS, O.F. 1982. Enzymatic hydrdrolysate of fish, spray dried fish solubles and soybean protein concentrate in milk replacers for calves. J. Dairy Sci., 65(12):2351-2356.

HUISMAN, J., VAN WEERDEN. Dietary fat for veal calves. In: ANNUAL MEETING OF THE EUROPEAN ASSOCIATION OR ANIMAL PRODUCTION, 35, 1984, Hague, Netherlands. Proceedings... Hague, 1984. 17p.

KEMPEN, G.J.M. van, HUISMAN, J. Introductory remarks: some aspects of skim-milk replacement by other protein sources in veal-calf diet. In: NEW TRENDS IN VEAL CALF PRODUCTION, 1991, Wageningem. Proceedings.... Wageningen, Netherlands, 1991. p.201-205.

KHORASANI, G.R., OZIMEK, L. J., SAUER, W.G. et al. 1989. Substitution of milk protein with isolated soy protein in calf milk replacers. J. Dairy Sci., 67(6):1634-1641.

KOLAR, C.W., WAGNER, T.J. Alternative protein use in calf milk replacers. In: NEW TRENDS IN VEAL CALF PRODUCTION, 1991, Wageningem. Proceedings.... Wageningen, Netherlands, 1991. p.211-216.

KNAUS,W., WETSCHEREK, W., LETTNER, F. 1994. Use of soy protein concentrate in combination with potato protein in milk replacers for veal calves. Anim. Feed Sci. Techn., 48(1-2):111-119.

LÁLLES, J.P. 1993. Nutritional and antinutritional aspects of soyabean and field pea proteins used in veal calf production: a review. Livest. Prod. Sci., 34(3-4):181-202.

LALLÉS, J.P., DRÉAU, D. 1996. Identification of soyabean allergens and immune mechanisms of dietary sensitivities in preruminant calves. Res. Vet. Sci., 60(2):111-116.

LAPORTE, A., DEMEERSMAN, M., LAPORTE, A. De. Soluble wheat protein in milk replacer for veal calves. In: NEW TRENDS IN VEAL CALF PRODUCTION, 1991, Wageningem. Proceedings.... Wageningen, Netherlands, 1991. p.222-226.

MILLER, B.L., PERRY, H.B., DEGREGORIO, R.M. et al. 1991. Performance of calves fed milk replacers containing different soy protein sources. J. Dairy Sci., 74(Suppl. 1):188.

NITSAN, Z.R., VOLCANI, R., GORDIN, S. et al. 1971. Growth and nutrient utilization by calves fed milk replacers containing milk or soybean protein concentrate toasted to various degrees. J. Dairy Sci., 54(9):1294-1299.

PETIT, H.V., IVAN, M., BRISSON, G.L. 1989. Digestibility measured by faecal and ileal collection in preruminant calves fed a clotting or a non-clotting milk replacer. J. Dairy Sci., 72(1):123-128.

QUIGLEY, J.D.III. Guide to modern calf milk replacers (10 Julh. 97). APCcalf notes. Http://www.americanprotein.com. Consultado em 24 de março de 1998.
RONDA, L.E., RONDA, C.J. 1994. Utilizacion de un hidrolizado, Becur, en terneros de engorde con lactorreemplazante. Avan. Alim. Mejora Anim., 34(6):15-21.

SEEGRABER, F.J., MORRILL, J.L. 1979. Effect of soy protein on intestinal absorptive ability of calves by the xilose absorption test. J. Dairy Sci., 62:972-977.

SEEGRABER, F.J., MORRILL, J.L. 1982. Effect of soy protein on calves intestinal absorptive ability and morphology determined by scanning electron microscopy. J. Dairy Sci., 65(10): 1962-1970.

SEEGRABER, F.J., MORRILL, J.E. 1985. Effect of feeding milk replacers containing high levels of soy flour heated for different intervals on calves intestinal ability and morphology. J. Dairy Sci., 68(Suppl. 1).

SEEGRABER, F.J., MORRILL, J.L. 1986. Effect of protein source in calf milk replacers on morphology and absorptive ability of small intestine. J. Dairy Sci., 69(2):460-469.

SILVA, A.G., CAMPOS, O.F. 1986. Fisiologia da digestão da proteína em bezerros durante o período pré-ruminante: Revisão da literatura. Pesq. Agropec. Bras., 21(7): 777-784.

SILVA, A.G., HUBER, J.T., DeGREGORIO, R.M. 1986. Influence of substituting two types of soybean protein for milk protein on gain and utilization of milk replacers in calves. J. Dairy Sci., 69(1):172-180.

SISSONS, J.W. 1982. Effects of soyabean products on digestive processes in the gastrointestinal tract of preruminant calves. Proc. Nutr. Society, 41(1):53-61.

TERNOUTH, J.J., ROY, J.H.B. 1973. The effect of diet and feeding technique on digestive function in the calf. Annls. Rech. Vétér., 4(1):19-30.

TOLMAN, G.H., DEMEERSMAN, M., METZ, J.H.M. et al. Digestibility and growth performance of soluble wheat protein for veal calves. In: NEW TRENDS IN VEAL CALF PRODUCTION, 1991, Wageningem. Proceedings.... Wageningen, Netherlands, 1991. p.227-233.

TOUlLEC, R., THERIEZ, M., THIVEND, P. 1980. Milk replacers for calves and lambs. World Anim. Rev., 33:32-42.

TOULLEC, R., Alimentation du veau de boucherie. In: ALIMENTATION DES BOVINS, OVINS ET CAPRINS, 1988, Paris: INRA, 1988. 471p.

TOULLEC, R., LALLES, J.P., BOUCHEZ, P. 1994. Replacement of skim milk with soya bean protein concentrates and whey in milk replacers for veal calves. Anim. Feed Sci. Techn., 50(1-2):101-112.

Recebido em: 03/05/00

Aceito em: 11/12/00 